\title{
Study of the Moisture Bond Forms in Cheeses
}

\author{
Vladimir Ermolaev 1,* (D) \\ 1 Department of Landscape Architecture, FSBEI HE Kuzbass State Agricultural Academy, Russia \\ * Correspondence: ermolaevvla@rambler.ru;
}

Scopus Author ID 57190978513

Received: 1.10.2020; Revised: 6.11.2020; Accepted: 9.11.2020; Published: 16.11.2020

\begin{abstract}
The article is devoted to the study of the forms of moisture bond in mature cheeses. The kinetics of mass transfer processes depend on the mobility and binding energy of water with solid and dissolved substances. Therefore, the removal of bound water is accompanied by deterioration in kinetics and increased energy consumption. In this regard, information on the state of bound water in substances during dehydration is very important from a scientific point of view and from a practical one. Based on the studies carried out, the forms of moisture bond in various types of cheese were determined by straingauge and thermographic methods. Based on this, it has been established that the forms of moisture bond in cheeses can be determined by strain-gauge and thermographic methods.
\end{abstract}

Keywords: moisture; water; cheeses; kinetics; thermographic methods.

(C) 2020 by the authors. This article is an open-access article distributed under the terms and conditions of the Creative Commons Attribution (CC BY) license (https://creativecommons.org/licenses/by/4.0/).

\section{Introduction}

Moisture removal from materials is accompanied by a violation of its connection with the consumption of certain energy; therefore, it is advisable to evaluate moisture-bound forms with the material using energy characteristics [1-4].

Academician P.A. Rehbinder, using the basic thermodynamic relations, gives a quantitative characterization of the binding energy of moisture with material and takes the value of the free energy of isothermal dehydration as the only criterion for classifying the forms of water bond with a material. The binding energy of moisture with the material, as defined by P.A. Rehbinder, equals to work spent to isolate one mole of water from the material without changing its aggregation state and is determined by the formula [5-9]:

$$
E=R \cdot T \cdot \ln \cdot\left(P_{O} / P_{W}\right)=-R \cdot T \cdot \ln \varphi,
$$

where $R$ - absolute gas constant, $\mathrm{kJ} /(\mathrm{kg} \cdot \mathrm{K})$;

$T$ - absolute temperature, $\mathrm{K}$;

$P_{O}$ - partial pressure of saturated vapor of free water over a flat surface at a given temperature, $\mathrm{mPa}$;

$P_{W}$ - partial pressure of saturated water vapor at the same temperature over the material, $\mathrm{mPa}$. $\left(P_{O} / P_{W}\right)=\varphi$, where $\varphi$ - relative humidity at equilibrium state, when the product does not absorb or lose water, fractions of units. 


\section{Materials and Methods}

Two of the most common and accurate methods were used to determine the forms of moisture bonding in cheeses: strain-gauge and thermographic. The use of two methods will make it possible to objectively determine the quantitative content of moisture bond forms in cheeses, as well as to assess the accuracy of the methods used [10,11].

The strain-gauge method for studying moisture bound with the material is to study sorption and desorption processes. In the strain-gauge method, the test samples of cheese were placed in weighing cups installed in desiccators. Sulfuric acid was preliminarily poured into each desiccator; its concentration corresponded to a certain relative humidity of the air. To obtain desorption isotherms, the studied cheeses samples were placed in 10 desiccators, where the relative air humidity was maintained from 10 to $100 \%$ with a step of $10 \%$. The cups with weighed samples of the material were periodically weighed until a constant mass was reached, which means the onset of an equilibrium state of the material with air in the desiccator. The standard method determines the moisture content of the material, which will be an equilibrium one. Then there will be a graphical relationship between the material's equilibrium moisture content and the air's relative humidity.

\section{Results and Discussion}

As a result of experimental studies, there were obtained nomograms to determine the forms and binding energy of moisture in cheeses (fig. 1-3).

These nomograms are based on isotherms of moisture desorption from cheese obtained by the strain-gauge method. Isotherms of moisture desorption from cheese have an S-shaped character, which is typical for capillary-porous colloidal materials. The nature of desorption isotherms depends on the type of moisture-material bond.

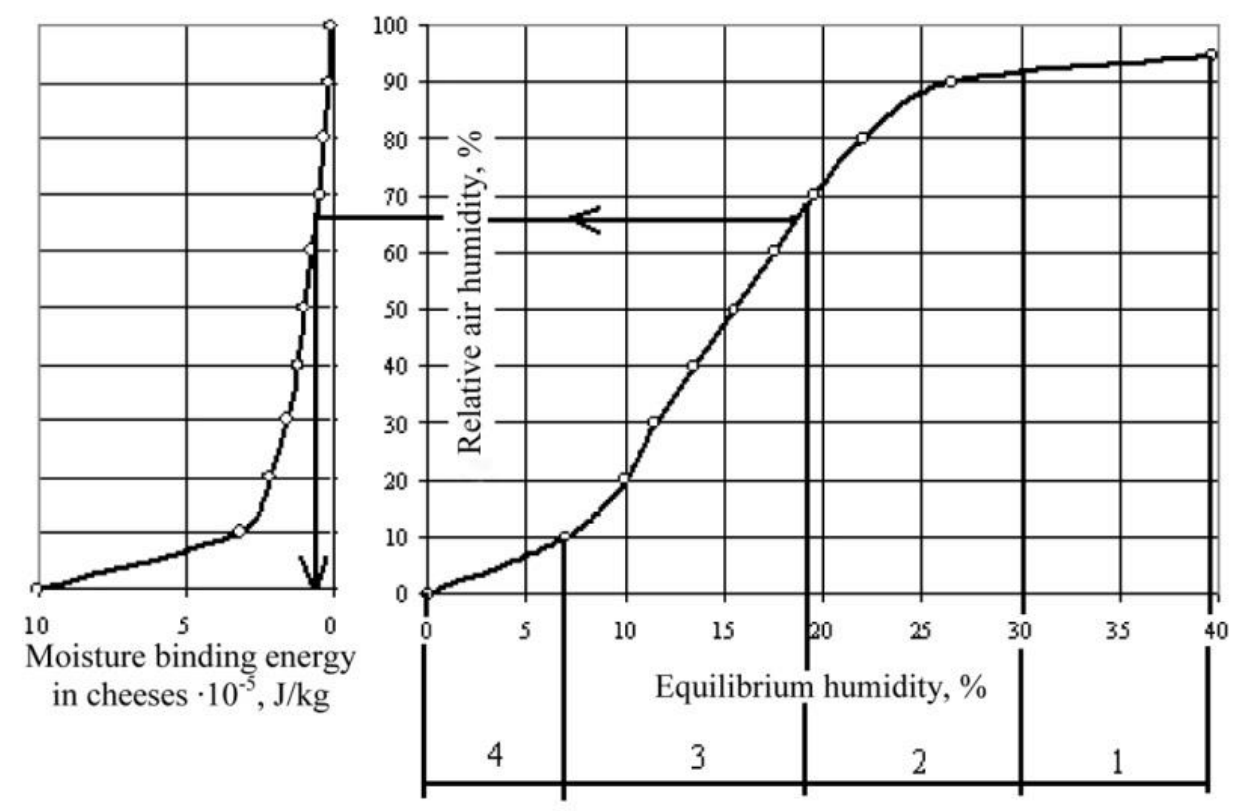

Figure 1. Nomogram for determining the forms and binding energy of moisture in cheese "Sovetskiy". 1-wetting moisture and macro-capillaries; 2-moisture of micro-capillaries and osmotic moisture;

3-moisture of poly-molecular adsorption; 4-moisture of monomolecular adsorption. 


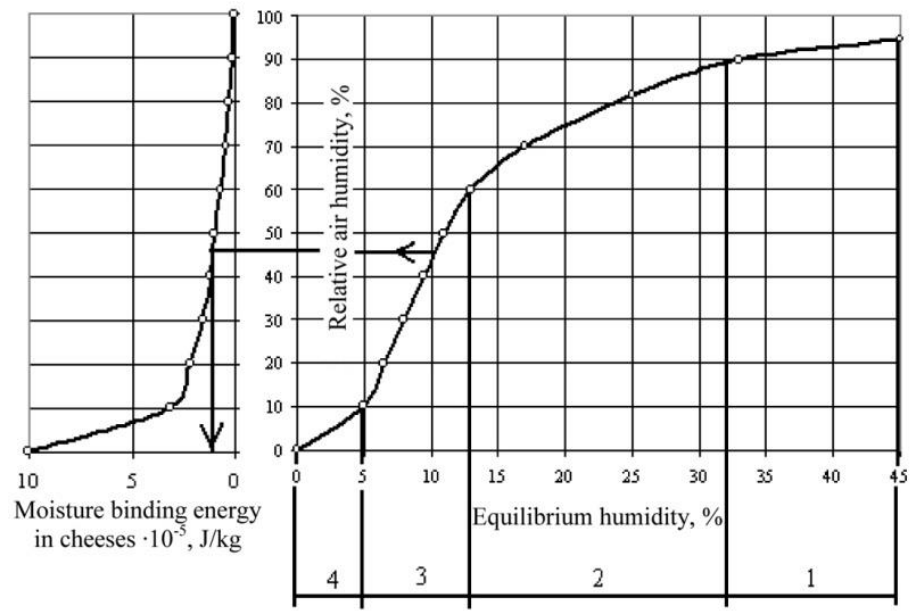

Figure 2. Nomogram for determining the forms and binding energy of moisture in the cheese "Gollandskiy". 1-wetting moisture and macro-capillaries; 2 - moisture of micro-capillaries and osmotic moisture;

3-moisture of poly-molecular adsorption; 4 - moisture of monomolecular adsorption.

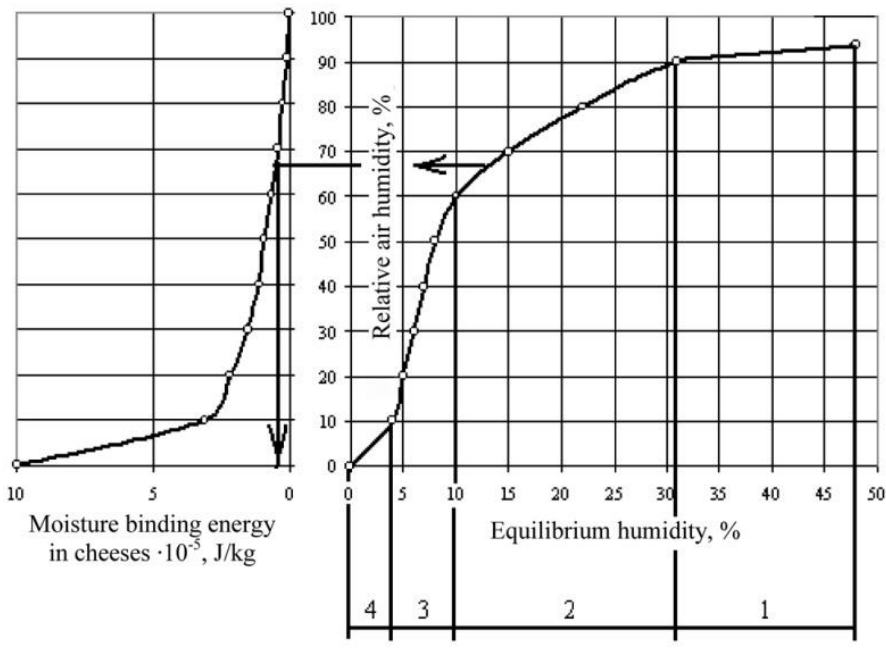

Figure 3. Nomogram for determining the forms and binding energy of moisture in the cheese "Ozernyy". 1-wetting moisture and macro-capillaries; 2 - moisture of micro-capillaries and osmotic moisture; 3-moisture of poly-molecular adsorption; 4 - moisture of monomolecular adsorption.

The cheeses' S-shaped isotherms of sorption and desorption initially in the region of low values of relative air humidity and equilibrium humidity up to a relative air humidity of $10-20 \%$ are convex to the abscissa axis, which corresponds to the moisture of monomolecular adsorption. The curve's convexity is then directed to the ordinate axis up to a relative humidity of $60-80 \%$. This area is characterized by poly-molecular moisture adsorption. Subsequently, the isotherm in the area of relative humidity after $60-80 \%$ smoothly passes to a flat curve inclined to the equilibrium humidity axis. Capillary condensation begins at the transition point.

According to the nomograms, the quantitative content of various forms and the binding energy of moisture in cheeses were determined (Tables 1,2).

Table 1.The quantitative content of various forms of moisture bond in cheeses, $\%$.

\begin{tabular}{|c|c|c|c|c|}
\hline \multirow[t]{3}{*}{ Type of cheese } & \multicolumn{3}{|c|}{ Physical-chemical bond } & \multirow{3}{*}{$\begin{array}{c}\begin{array}{c}\text { Physical-mechanical } \\
\text { bond }\end{array} \\
\text { moisture of wetting } \\
\text { and macro-capillaries }\end{array}$} \\
\hline & \multicolumn{2}{|c|}{ adsorbed bound moisture } & \multirow{2}{*}{$\begin{array}{l}\text { osmotically bound moisture and } \\
\text { moisture of micro-capillaries }\end{array}$} & \\
\hline & monomolecular & polymolecular & & \\
\hline «Sovetskiy» & 7,0 & 11,0 & 12,0 & 10,0 \\
\hline «Gollandskiy» & 5,0 & 8,0 & 19,0 & 12,0 \\
\hline «Ozernyy» & 4,0 & 6,0 & 21,0 & 17,0 \\
\hline
\end{tabular}


It should be clarified that the moisture mass fraction in the cheeses was the following: "Sovetskiy" - 40\%, "Gollandskiy" - 44\%, "Ozernyy" - 48\%. The highest content of bound moisture is found in "Sovetskiy" cheese - 18.0\%, "Gollandskiy" - 13.0\%, "Ozernyy" - 10.0\%. "Sovietskiy" cheese with the smallest amount of total moisture of the three considered brands of cheeses contains the largest amount of bound moisture. The content of energy-intensive bonds in cheeses depends on their production technology and the ripening process's duration.

P.F. Krashenin, V.P. Tabachnikov [12] found a general increase in water-holding capacity as the cheese ripens. The duration of ripening can be taken into account as a first approximation as a factor on which the amount of bound moisture in the cheese depends - the longer the ripening process is, the more bound moisture is contained in the cheese. These dependencies in good agreement with our results [13-17].

Table 2.Moisturebindingenergy in cheeses $\cdot 10^{-5}, \mathrm{~J} / \mathrm{kg}$.

\begin{tabular}{l|l|l|l}
\multirow{2}{*}{ Form of moisture bond with the material } & Type of cheese \\
\cline { 2 - 4 } & «Sovetskiy» & «Gollandskiy» & «Ozernyy» \\
\hline Physical-chemical bond & $4,20-2,70$ & $3,90-2,50$ & $3,40-2,50$ \\
\hline Monomolecularadsorption & $2,20-0,50$ & $2,30-0,70$ & $2,20-0,70$ \\
\hline polymolecular adsorption & $0,45-0,12$ & $0,65-0,10$ & $0,60-0,10$ \\
\hline osmotically bound moisture & $0,45-0,12$ & $0,65-0,10$ & $0,60-0,10$ \\
\hline Physical-mechanical bond & $<0,10$ & $<0,10$ & $<0,10$
\end{tabular}

The studies carried out have shown that the energy characteristics of dissimilarly bound moisture are different. However, when passing from free moisture (wetting and microcapillaries) to bound moisture (mono- and polymolecular adsorption), moisture's binding energy with dry cheese substance increases significantly.

The binding energy $\left(10^{5}, \mathrm{~J} / \mathrm{kg}\right)$ for wetting moisture and macro-capillaries is $<0.10$, for osmotically bound moisture and micro-capillary moisture, it is $0.45-0.12$, for poly-molecular adsorption moisture - 2.30-0.50, and the moisture of monomolecular adsorption - 4.20-2.50. Consequently, mono- and polymolecular adsorption moisture due to the highest binding energy is strongly bound. In this connection, it is obvious that the moisture of monomolecular adsorption is the main indicator of the hydration of the constituent parts of the product and is important for the recoverability of food after drying. Table 3 shows the hygroscopic characteristics of the cheeses.

Table 3. Hygroscopic characteristics of cheeses.

\begin{tabular}{|c|c|c|c|c|c|c|c|c|c|}
\hline Relative air humidity, \% & 10 & 20 & 30 & 40 & 50 & 60 & 70 & 80 & 90 \\
\hline \multicolumn{10}{|l|}{ «Sovietskiy» cheese } \\
\hline Equilibrium moisture, $\%$ & 7,0 & 10,0 & 11,5 & 13,5 & 15,5 & 17,5 & 19,5 & 22,0 & 26,5 \\
\hline \multicolumn{10}{|l|}{ «Gollandskiy»cheese } \\
\hline Equilibrium moisture, $\%$ & 5,0 & 6,5 & 8,0 & 9,5 & 11,0 & 13,0 & 17,0 & 25,0 & 33,0 \\
\hline \multicolumn{10}{|l|}{ «Ozernyy»cheese } \\
\hline Equilibrium moisture, $\%$ & 4,0 & 5,0 & 6,0 & 7,0 & 8,0 & 10,0 & 15,0 & 22,0 & 31,0 \\
\hline
\end{tabular}

According to table 3, it can be seen that if the relative humidity of the air decreases, the equilibrium moisture content of the product decreases as well. With a simultaneous decrease in the equilibrium air humidity, there is an increase in moisture's binding energy with the product's dry part. At a relative humidity of less than $40 \%$, a sharp increase in the binding energy with the material occurs. With a decrease in the material's moisture content, the 
proportion of removed moisture increases, which is adsorptively bound to the substance [1821].

A.S. Ginzburg [22] notes that the analysis of thermographs of heating a wet material during the drying process according to the method of M.F. Kazanskiy [23] gives results consistent with the analysis of sorption isotherms. In this connection, the current research was to determine the forms of moisture bond in cheeses using thermographs of M.F. Kazanskiy [23]. Moisture bond forms were determined in the same cheese samples that were used in the strain-gauge method.

For the drying process, it is very important to link the classification of the forms of water bond with the state of the material directly during the drying process. Therefore, the thermographic method for analyzing the types of moisture-material bonds proposed by M.F. Kazanskiy [23] is of great interest. According to this method, there was carried out the analysis of thermographs characterizing the change in temperature of a thin sample of cheese in the process of slow isothermal drying. Under such experiments' conditions, the sample's temperature and humidity fields are close to uniform ones.

The advantage of this method is its speed compared to the considerable duration of removing sorption isotherms. Simultaneously, this method makes it possible to visualize the kinetics of sequential removal of water from a thin layer of water of various forms and types of connection with the material skeleton. In the course of taking thermographs during isothermal drying of cheese, the weight of the dried cheese sample was also controlled.

Figures 4-6 show thermographs of isothermal drying of cheese and graphs of changes in weight, cheese samples in the process of isothermal drying. Based on the analysis of drying thermographs and graphs of weight change, a number of singular points were established that characterize various forms of moisture bound in cheeses. The thermographs' characteristic points determine the beginning of removing moisture that is differently bound with the material at different stages of the drying process. On the thermographs of cheese drying, the four most characteristic areas can be noted.

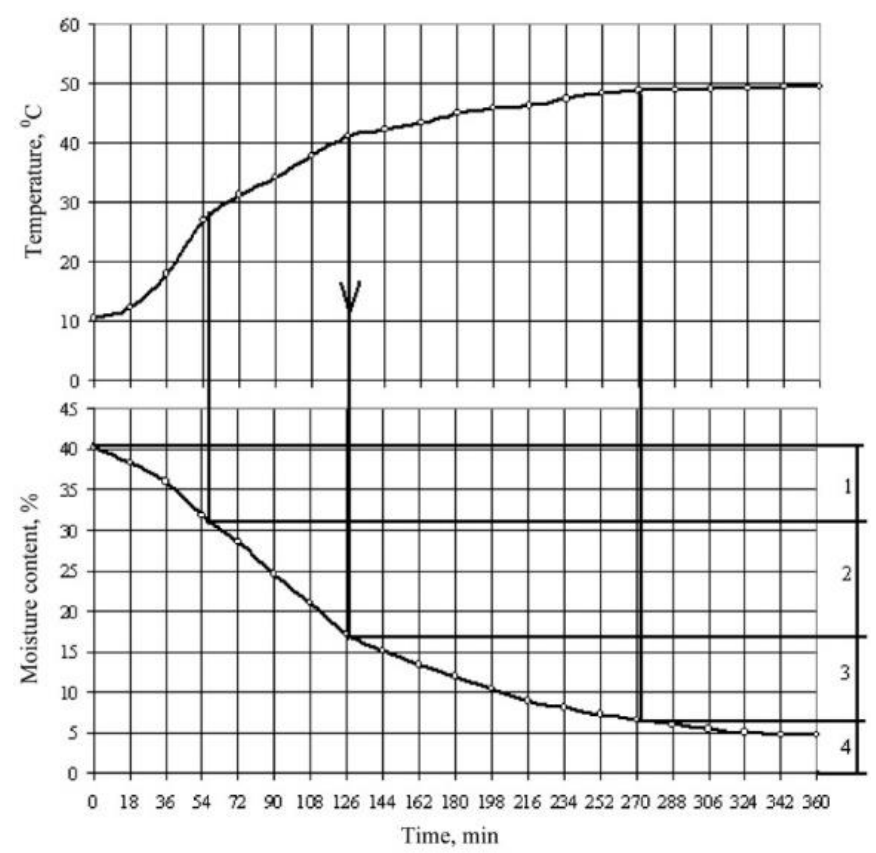

Figure 4. Thermographs of isothermal cheese drying and graphs of changes in the mass of "Sovietskiy" cheese in the process of isothermal drying: 1 - moisture of wetting and macro-capillaries; 2 - moisture of microcapillaries and osmotic moisture; 3 - moisture of polymolecular adsorption; 4 - moisture of monomolecular adsorption. 


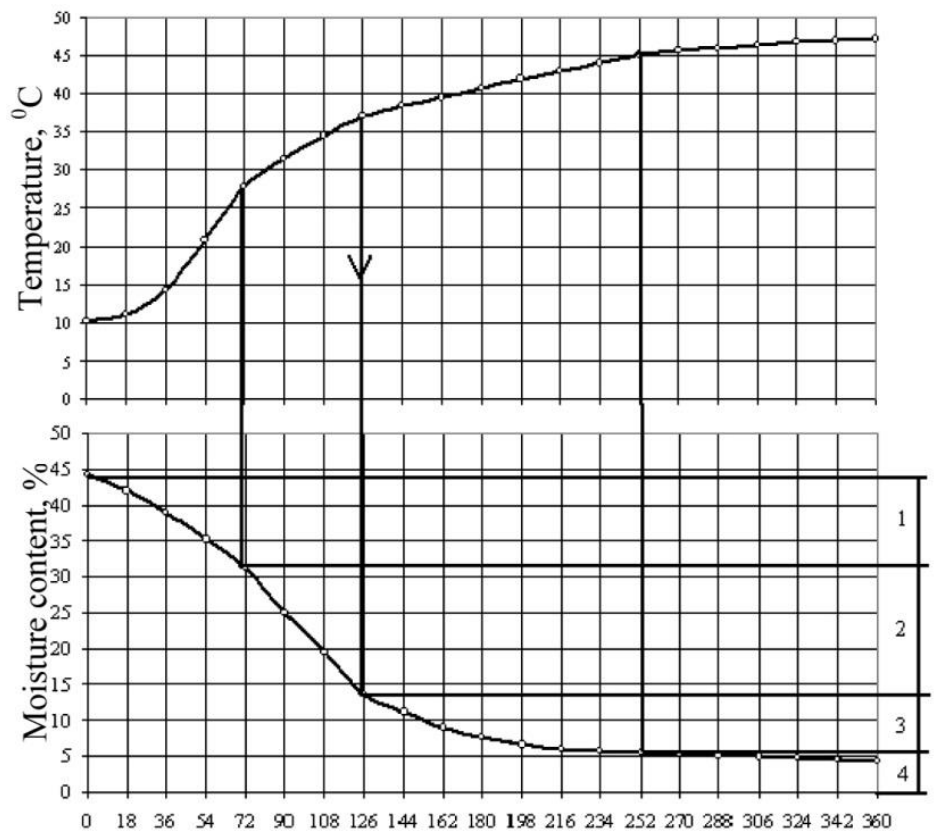

Time, $\min$

Figure 5. Thermographs of isothermal cheese drying and graphs of changes in the mass of "Gollandskiy" cheese in the process of isothermal drying: 1 - wetting moisture and macro-capillaries; 2 - moisture of micro-capillaries and osmotic moisture; 3 - moisture of polymolecular adsorption; 4 - moisture of monomolecular adsorption.

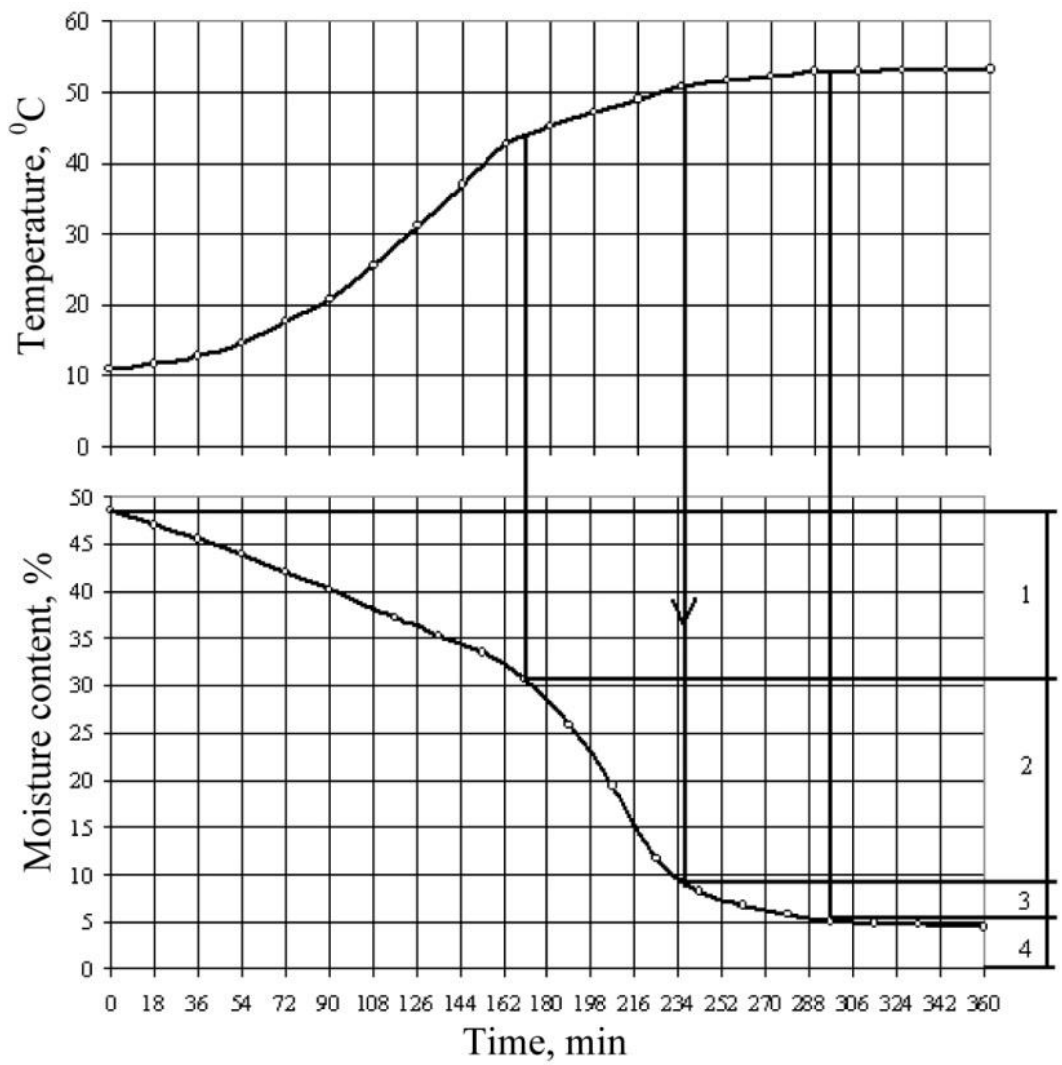

Figure 6. Thermographsof isothermal cheese drying and graphs of changes in the mass of "Ozernyy" cheese in the process of isothermal drying: 1 - wetting moisture and macro-capillaries; 2 - moisture of micro-capillaries and osmotic moisture; 3 - moisture of polymolecular adsorption; 4 - moisture of monomolecular adsorption.

Micro-capillaries' moisture is located in capillaries (pores) with an average radius greater than $10-5 \mathrm{~cm}$. The partial pressure of water vapor above the macro-capillary meniscus is almost the same as the partial pressure of saturated vapor above the free water's surface. 
The first section of the thermographs smoothly turns into the second. Suppose the first section shows the heating of the material in volume and an increase in the drying rate. In that case, the second section is characterized by a constant drying rate. According to a linear law, an increase in temperature and a decrease in the mass fraction of moisture in cheese occur.

In the second period, moisture from micro-capillaries and osmotic moisture is removed. The micro-capillaries' moisture fills narrow pores, the average radius of less than $10-5 \mathrm{~cm}$. The liquid fills any micro-capillaries, not only in direct contact but also by the moist air's sorption. The moisture of micro-capillaries moves in the body both in the form of a liquid (usually from the central layers to the evaporation zone) and vapor (from the evaporation zone through the dry layer to the outside).

Osmotically bound moisture is absorbed by a complexly structured micelle (theory of S.M. Lipatov) [24], and immobilization moisture (theory of P.A.Rebinder) [25], captured during the formation of the gel. This moisture is free as it corresponds to a very low binding energy.

The second section's point of transition to the third one corresponds to the maximum hygroscopic moisture content. To the right of it, a period of decreasing drying speed begins. The beginning of the third section corresponds to the removal of the physicochemical form of the bond. This form corresponds to adsorbed moisture.

Adsorptionbound moisture has a number of properties that distinguish it from ordinary, free water. Films of bound water in their physical properties resemble more a solid form than a liquid one. Moreover, the strictly defined orientation of the molecules brings them closer to the crystalline substance.

Adsorption bound moisture is a liquid retained by a force field on the outer and inner surfaces of "micelles" - colloidal particles. Colloidal materials (bodies) are characterized by a very significant particle size, the conditional radius of which is $0.1-0.001$ microns.

The adsorbed moisture is divided into mono- and polymolecular adsorption moisture. The greatest amount of heat is released when the first monomolecular layer is attached, which is most strongly associated with the material. S.M. Lipatov [24] proved the thermal analogy of the processes of swelling and dissolution. The removal of adsorptive moisture firmly bound to the body is associated with corresponding energy expenditure. A.V. Lykov [26] found that to remove adsorptive moisture, it must be converted into vapor, after which it begins to move to the body's outer surface.

The $\mathrm{m}$, The moisture of polymolecular adsorption, is removed during the third section. In the fourth section, moisture is removed by monomolecular adsorption.

Thus, the joint analysis of the graphs of changes in mass and thermographs, that display the thermodynamic picture of the drying process of cheese samples and show the dependence of mass transfer on the types of connection, determines the boundaries of the periods of removal of individual forms and types of connection of moisture with the material. By the critical points of the thermograph located at these boundaries and by the drying curve, it is possible to accurately determine the mass fraction of moisture at a given time.

The quantitative content of various forms of moisture bond in cheeses, determined by using thermographs of isothermal drying of cheese and graphs of changes in weight, cheese samples in the process of isothermal drying is given in the table 4.

With the help of mathematical modeling of the graphs of changes in the mass of "Sovietskiy", "Gollandskiy" and "Ozernyy" cheese shown in Fig. 4-6, the equations are 
obtained for calculating the mass fraction of cheese moisture depending on the duration of drying.

Table 4. The quantitative content of various forms of moisture bonds in cheeses determined by using thermographs of isothermal drying, $\%$.

\begin{tabular}{|c|c|c|c|c|}
\hline \multirow[t]{3}{*}{ Types of cheese } & \multirow{2}{*}{\multicolumn{2}{|c|}{$\begin{array}{c}\text { Physical-chemical bond } \\
\text { adsorbed bound moisture }\end{array}$}} & \multicolumn{2}{|c|}{ Physical-mechanical bond } \\
\hline & & & \multirow{2}{*}{$\begin{array}{c}\text { osmotically bound moisture and } \\
\text { moisture of micro-capillaries }\end{array}$} & \multirow{2}{*}{$\begin{array}{c}\text { moisture of wetting } \\
\text { and macro-capillaries }\end{array}$} \\
\hline & monomolecular & polymolecular & & \\
\hline "Sovietskiy" & 7,0 & 10,0 & 14,0 & 9,0 \\
\hline "Gollandskiy" & 5,0 & 8,0 & 18,0 & 13,0 \\
\hline "Ozernyy" & 4,0 & 5,0 & 22,0 & 17,0 \\
\hline
\end{tabular}

For "Sovietskiy" cheese:

$$
W=44,417 \cdot e^{-1,49 \cdot 10^{-3} \cdot t}
$$

For "Gollandskiy" cheese:

$$
W=43,672 \cdot e^{-0,0017 \cdot t}
$$

For "Ozernyy" cheese:

$$
W=80,208 \cdot e^{-0,0018 t},
$$

where ${ }^{t}$ - drying time, minutes.

Thus, based on the studies carried out, the forms of moisture-binding in various types of cheese were determined by strain-gauge and thermographic methods. Differences in the forms of moisture bonds in cheeses determined by two methods do not exceed 1-2\%. Based on this, it has been established that the forms of moisture bond in cheeses can be determined by strain-gauge and thermographic methods. It should be noted that the disadvantage of the strain gauge method for determining the forms of moisture bond in the product is its duration since the equilibrium humidity between the product and the surrounding air occurs on average in 2030 days. This situation's thermographic method can be called an express method; the thermograph recording duration is 6-7 hours.

The specific heat of moisture evaporation is of considerable interest in studying the drying process of food products. Figure 7 shows the results of studies on the specific heat of evaporation from cheeses with a different mass fraction of moisture.

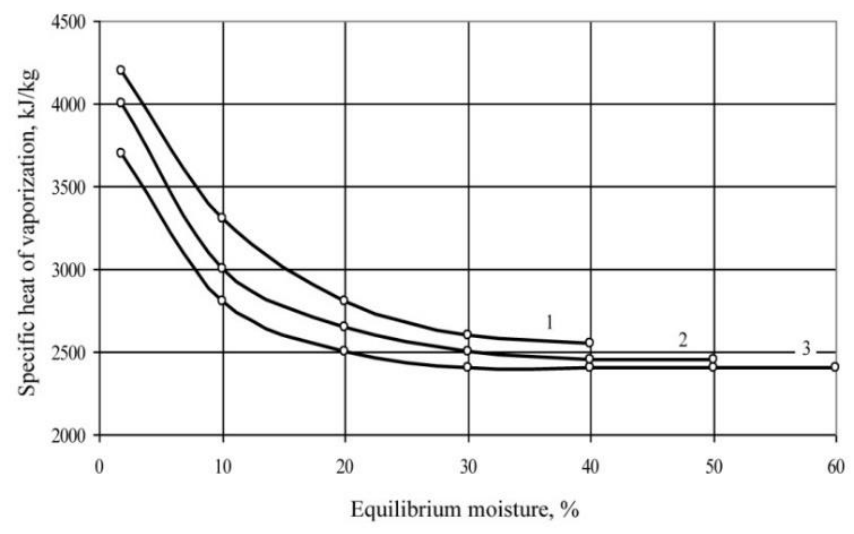

Figure 7.Energygraphs of isothermal cheese drying with a mass fraction of moisture.

$$
1-40 \% ; 2-50 \% ; 3-60 \%
$$

The specific heat of vaporization was produced on an automated calorimeter based on automatic compensation of the heat spent on moisture evaporation. In this case, the heat spent on evaporation of moisture is used to convert water into steam and break the bond between 
moisture and material. Isothermal drying of cheeses was carried out at $50{ }^{\circ} \mathrm{C}$. It is known that the specific heat of vaporization of water is approximately equal to $2400 \mathrm{~kJ} / \mathrm{kg}$.

Regardless of the cheese mass fraction from the beginning of the experiment to an equilibrium moisture content of $30 \%$, the specific heat of vaporization was at the level of 2400$2700 \mathrm{~kJ} / \mathrm{kg}$. This confirms that the evaporation of wetting moisture and macro-capillaries occurs. The specific heat of vaporization increases from 30 to 15\%, while micro-capillaries' moisture and osmotic moisture are removed.

A significant increase in the specific heat of vaporization occurs in the range of equilibrium air humidity from 15 to $2 \%$, with moisture removal from poly- and monomolecular adsorption.

A monotonic increase in the specific heat of evaporation with a decrease in the equilibrium humidity indicates the imposition of the thermal effects of evaporation of various moisture types. That is, various types of moisture bonds are removed not sequentially one after another, but simultaneously.

It should be noted that the lower the mass fraction of moisture in the original cheese is, the higher the specific heat of evaporation at the same equilibrium moisture content presents. So, at an equilibrium moisture content of $30 \%$ for cheese with a mass fraction of moisture $40 \%$, the specific heat of vaporization is $2600 \mathrm{~kJ} / \mathrm{kg}, 50 \%-2500 \mathrm{~kJ} / \mathrm{kg}, 60 \%-2400 \mathrm{~kJ} / \mathrm{kg}$; at an equilibrium humidity of 10\%: $40 \%-3300,50 \%-3000,60 \%-2800 \mathrm{~kJ} / \mathrm{kg}$; at an equilibrium moisture content of $2 \%: 40 \%-4200,50 \%-4000,60 \%-3700 \mathrm{~kJ} / \mathrm{kg}$.

There are no sharp boundaries between the heat of evaporation of capillary-bound moisture and moisture of polymolecular adsorption. As the adsorbed moisture evaporates up to the equilibrium moisture content corresponding to the filling of the monolayer, the curves of the specific heat of evaporation smoothly rise upward; then, with a further decrease in the equilibrium moisture content, a steep rise in the curves is observed for all the studied cheeses. Of greatest importance are the heats of evaporation of monomolecular adsorption moisture, firmly associated with cheeses' dry matter.

The division of moisture into levels is largely arbitrary since moisture distribution in the cheese mass by binding energies is constantly changing. We should talk about a dynamic balance between certain values of energies at specific stages of cheese production, that is, there is a spectrum of binding energies of water in the cheese mass, which is continuous in the range from minimum values corresponding to free moisture to maximum values corresponding to the moisture of monomolecular adsorption.

Experimental measurement of the activation energy gives sufficient accuracy in assessing the levels of the binding energy of moisture in the material. The thermographic method of measurement obtained the binding energy (activation) of water in the cheese "Ozernyy", "Gollandskiy", "Sovietskiy" in the energy range from 10 to 4200 kJ/kg (fig. 8).

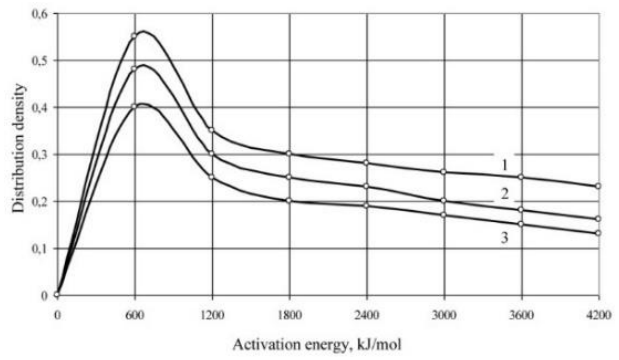

Figure 8. Graphs of the statistical distribution of the activation energy of water in cheese.

1 - "Ozernyy"; 2 - "Gollandskiy"; 3 - "Sovietskiy" 
The energy graphs analysis showed that the greatest changes in water distribution in the three types of studied cheeses occur according to the same patterns. In all studied cheeses, an increase in the proportion of water with binding energy from 200 to $1200 \mathrm{~kJ} / \mathrm{kg}$ was observed due to a decrease in its amount in the energy range from 5 to $100 \mathrm{~kJ} / \mathrm{kg}$.

This is due to the formation of mono- and polymolecular layers of water. From the point of view of technology, the most important is water with average values of binding energies: adsorbed-bound and osmotically retained, since it plays a decisive role in the formation of consistency, determines the rheological parameters of cheeses of conditioned maturity.

\section{Conclusions}

The following results were obtained based on the studies carried out:- forms of moisture bound in various types of cheese have been determined by strain-gauge and thermographic methods. Differences in the forms of moisture bonding in cheeses determined by two methods do not exceed 1-2\%. On the basis of this fact, it has been established that the forms of moisture bond in cheeses can be determined by strain-gauge and thermographic methods. It should be noted that the disadvantage of the strain gauge method for determining the forms of moisture bond in the product is its duration. The equilibrium humidity between the product and the surrounding air occurs on average in 20-30 days. The thermographic method in this situation can be called an express method; the thermograph recording duration is 6-7 hours;- the specific heats of evaporation of moisture from cheeses with different moisture content were determined by using an automated calorimeter. It has been established that the highest value of the specific heat of vaporization has the moisture of monomolecular adsorption;- thermographic method of measurement obtained the activation energy of water in the cheese "Ozernyy", "Gollandskiy", "Sovietskiy". The graphs of the static distribution of the water activation energy in cheeses confirm the content of various forms of moisture bond in cheeses determined by strain-gauge and thermographic methods.

Foods usually contain both bound and free moisture at the same time. The quantitative relationship between them depends on the nature of a particular object. For the drying process, it is very important to link the classification of the forms of water connection with the state of the material directly during the drying process.

The obtained data on the forms of moisture bond in cheeses must be used to correct the drying process. The drying mechanism of wet materials is mainly determined by the form of moisture-material bond and the drying mode. The kinetics of mass transfer processes depend on the mobility and binding energy of water with solid and dissolved substances. Therefore, the removal of bound water is accompanied by deterioration in kinetics and increased energy consumption. In this regard, information on the state of bound water in materials during dehydration is very important not only from a scientific but also from a practical point of view since it opens up the possibility of predicting and optimizing drying.

\section{Funding}

This research received no external funding.

\section{Acknowledgments}

This research has no acknowledgment. 


\section{Conflicts of Interest}

The funders had no role in the study's design; in the collection, analyses, or interpretation of data; in the writing of the manuscript, or in the decision to publish the results.

\section{References}

1. Ermolaev, V.A. Development of mathematical model for vacuum cheese drying. Biointerface Research in Applied Chemistry 2019, 9, 3830-3833, https://doi.org/10.33263/BRIAC91.830833.

2. Gorelik, O.; Harlap, S.; Gorelik, A.; Dolmatova, I.; Zalilov, R.; Dogareva, N.; Fedoseeva, N.; Delian, A.; Ermolaev, V. The state of nonspecific resistance of calves during the preweaning period. International Journal of Pharmaceutical Research 2019, 11, 1775-1780, https://doi.org/10.31838/ijpr/2019.11.01.133.

3. Ermolaev, V.A.; Yashalova, N.N.; Ruban, D.A. Cheese as a Tourism Resource in Russia: The First Report and Relevance to Sustainability. Sustainability 2019, 11, https://doi.org/10.3390/su11195520.

4. Kechkin, I.A.; Ermolaev, V.A.; Ivanov, M.V.; Romanenko, A.I.; Gurkovskaya, E.A.J.B.W.C. Dependence of fat acidity value on wheat grain storage conditions. BIO Web of Conferences 2020, 17, https://doi.org/10.1051/bioconf/20201700107.

5. Kechkin, I.A.; Ermolaev, V.A.; Romanenko, A.I.; Tarakanova, V.V.; Buzetti, K.D.J.B.W.C. Management of air flows inside steel silo during grain storage.BIO Web of Conferences 2020, 17, https://doi.org/10.1051/bioconf/20201700108.

6. Ermolaev, V.A.; Ruban, D.A.; Yashalova, N.N.; Latushko, N.A.; Loon, A.J. Missions of Russian Cheese Producers: Principal Components and Relevance for Rural Communities. Agriculture 2020, 10, https://doi.org/10.3390/agriculture10030068.

7. Ermolaev, V.A. The study of the microstructure of cheese before and after vacuum drying. Biointerface Research in Applied Chemistry 2020, 10, 6007-6014, https://doi.org/10.33263/BRIAC104.007014.

8. Ermolaev, V.A.; Kechkin, I.A.; Romanenko, A.I. Research of Vacuum Honey Drying Processes. Proceedings of the International Conference on Policies and Economics Measures for Agricultural Development 2020, 147, https://doi.org/10.2991/aebmr.k.200729.015.

9. Patil, G.K.; Patil, P.B.; Pardeshi, S.R.; Rajput, R.L.; Sonawane, S.H.; Mujumdar, A.; Naik, J.B. Effect of process parameters on the recovery of lactose in an antisolvent acetone/acetone-ethanol mixture: A comparative study based on sonication medium. Ultrasonics Sonochemistry 2020, 67, https://doi.org/10.1016/j.ultsonch.2020.105128.

10. Stenström, S. Drying of paper: A review 2000-2018. Drying Technology 2020, 38, 825-845, https://doi.org/10.1080/07373937.2019.1596949.

11. Salamat, R.; Scaar, H.; Weigler, F.; Berg, W.; Mellmann, J. Drying of biogas digestate: A review with a focus on available drying techniques, drying kinetics, and gaseous emission behavior. Drying Technology 2020, 25, https://doi.org/10.1080/07373937.2020.1781879.

12. Kornelyuk, B.V. The use of a differential scanning calorimeter to determine bound water in cheese / B.V. Kornelyuk, P.F. Krasheninin, V.P. Tabachnikov // Improvement of production control methods and improvement of product quality in the cheese-making and butter-making industry: VNIIMSP, Proceedings. - Issue. 21. - M., 1977. - P. 93-95.

13. Rezvankhah, A.; Emam-Djomeh, Z.; Askari, G. Encapsulation and delivery of bioactive compounds using spray and freeze-drying techniques: A review. Drying Technology 2020, 38, 235-258, https://doi.org/10.1080/07373937.2019.1653906.

14. Mi, S.; Liu, Z.; Luo, C.; Cai, L.; Zhang, Z.; Li, L. A review on preparing new energy ultrafine powder materials by freeze-drying. Drying Technology 2020, 38, 1544-1564, https://doi.org/10.1080/07373937.2019.1651733.

15. Masum, A.K.M.; Chandrapala, J.; Huppertz, T.; Adhikari, B.; Zisu, B. Production and characterization of infant milk formula powders: A review. Drying Technology 2020, 21, https://doi.org/10.1080/07373937.2020.1767645.

16. Harguindeguy, M.; Fissore, D. On the effects of freeze-drying processes on the nutritional properties of $\begin{array}{lllllll}\text { foodstuff: } & \text { A } & \text { review. } & \text { Drying } & \text { Technology } & \text { 2020, }\end{array}$ https://doi.org/10.1080/07373937.2019.1599905.

17. dos Reis, R.F.; Sergio Cordeiro, J.; Font, X.; Laguna Achon, C. The biodrying process of sewage sludge - a review. Drying Technology 2020, 38, 1247-1260, https://doi.org/10.1080/07373937.2019.1629689.

18. Chavan, A.; Vitankar, V.; Mujumdar, A.; Thorat, B. Natural convection and direct type (NCDT) solar dryers: a review. Drying Technology 2020,22, 1-22, https://doi.org/10.1080/07373937.2020.1753065.

19. Yi, J.; Li, X.; He, J.; Duan, X. Drying efficiency and product quality of biomass drying: a review. Drying Technology 2019,16, 1-16, https://doi.org/10.1080/07373937.2019.1628772.

20. Subrot Panigrahi, S.; Singh, C.B.; Fielke, J.; Zare, D. Modeling of heat and mass transfer within the grain storage ecosystem using numerical methods: A review. Drying Technology 2020, 38, 1677-1697, https://doi.org/10.1080/07373937.2019.1656643. 
21. Liu, M.; Xu, C.; Han, X.; Liu, R.; Qin, Y.; Yan, J. Integration of evaporative dryers into lignite-fired power plants: A review. Drying Technology 2019, 19, 1-19, https://doi.org/10.1080/07373937.2019.1606824.

22. Ginzburg, A.S. Thermophysical characteristics of food products: a reference book / A.S. Ginzburg, M.A. Gromov, G.I. Krasovskaya. - Agropromizdat, 1990. - 295 p.

23. Kazanskiy, M.F. Infrared technology in the food industry / M.F. Kazanskiy. - Food industry, 1996. - 470 p.

24. Lipatov, N.N. Intensification of technological processes with the help of evacuation: overview information / N.N. Lipatov. - Agro, 1987. - 42 p.

25. Rebinder, P.A. Surface phenomena in dispersed systems. Colloid chemistry. Selected Works / P.A. Rebinder. - Moscow: Nauka, 1978. - 368 p.

26. Lykov, A.V. The theory of drying capillary-porous colloidal materials for the food industry / A.V. Lykov. Pishche-promizdat, 1996. - 287 p. 